\title{
Fault area estimation using traveling wave for wide area protection
}

\author{
Jae-Won LEE ${ }^{1}$, Won-Ki KIM ${ }^{2}$, Joon HAN ${ }^{1}$, Won-Hyeok JANG ${ }^{3}$, \\ Chul-Hwan KIM ${ }^{1}$
}

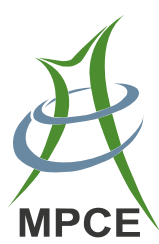

\begin{abstract}
As the increasing number of Phasor Measurement Units (PMUs) are deployed, wide area protection in power systems has been gaining interest. In particular, fault detection, fault classification and fault area estimation are essential to reduce the damage of faults, and even prevent catastrophic cascades of failures. In this paper, we present a scheme for fault area estimation using PMUs and traveling wave theory. The purpose of this paper is to formulate a scheme for fault area estimation by calculating the approximate fault location based on traveling wave theory. This research has targeted at reliable operation of wide transmission system through the estimation of fault area. To verify the suggested scheme, the various simulations are performed in practical Korean power transmission system.
\end{abstract}

CrossCheck date: 27 June 2016

Received: 18 August 2015/Accepted: 28 June 2016/Published online: 18 July 2016

(C) The Author(s) 2016. This article is published with open access at Springerlink.com

$\triangle$ Chul-Hwan KIM

hmwkim@hanmail.net

Jae-Won LEE

daniel701@hanmail.net

Won-Ki KIM

kimwonki87@hanmail.net

Joon HAN

j3angh@gmail.com

Won-Hyeok JANG

wjang7@illinois.edu

1 Department of Electrical and Computer Engineering, Sungkyunkwan University, Suwon, Republic of Korea

2 Daewoo Shipbuilding \& Marine Engineering Co., Ltd., Geoje, Republic of Korea

3 Electrical and Computer Engineering Department, University of Illinois at Urbana-Champaign, Champaign, IL, USA
The simulation results show that the proposed scheme has a good performance with high accuracy for estimating fault area.

Keywords Fault area estimation, Phasor measurement unit (PMU), Transmission line system, Traveling wave, Wide area protection

\section{Introduction}

Wide area protection schemes should be more intelligent to deal with new challenges, as the structure of power system have become more complex along with the development of distributed generations and renewable energy sources. Furthermore, the fast and accurate methods to detect faults, classify their types and locate them are crucial in wide area power systems. In order to address these challenges, the various practical researches related to the wide area protection schemes have been studied in many countries in the past few years [1-13].

In the 1980s, many researchers began studies on new technologies such as Power System Disturbance Monitor (PSDM), Frequency Disturbance Recorder (FDR), and PMUs based on the Global Positioning System (GPS) to prevent wide area blackout and to monitor, analyze and control wide area power grids [1, 2]. In U.S.A, Frequency Monitoring Network (FNET) has been constructed and is being operated by the Electric Power Research Institute (EPRI), Tennessee Valley Authority (TVA), and the IT Research Center at Virginia Tech University [5, 6].

In Korea, Korea-Wide Area Measurement System (KWAMS) has been developed by Korea Electro- technology Research Institute (KERI), Korea Electric Power Corporation (KEPCO), Korea Electric Power Knowledge Data 
Network (KDN), and LS Industrial Systems (LSIS). $\mathrm{K}$-WAMS monitors and evaluates wide-area power grids using the synchro-phasor of the voltages and currents measured by Intelligent Power system Information Unit (IPIU) [7]. Recently, Wide Area Monitoring And Control (WAMAC) system has been considered as a new wide area protection system. According to the KERI's research result, WAMAC system is expected to detect unstable condition of power system beforehand and to prevent wide area outage from happening by blocking the faulted parts. In short, the various methods and systems are getting more attention because they could contribute to the prevention of cascaded power system failures [3-13].

As mentioned above, there are so many efforts to protect wide area power system. When these schemes are used as a kind of solution, the most important first step for protecting wide area power system is to detect the fault area. Once the accurate fault location is distinguished from wide area power system, it is possible to only separate the fault location. After the fault in power system is cleared, the restoration of power system will be achieved and then the wide area power system can come back to the steady state. In the series of process above, the discrimination of fault location is the most important basic stage for protecting power system.

In the past few years, fault location estimation has been performed in several methods, for example wavelet transform [14], fuzzy logic, neural networks [15], distributed parameter of transmission line [16], traveling wave method [17], prony method [18] and impedance method [19, 20]. Among them, the main fault location detection methods are impedance method and traveling wave method. Especially, the travelling wave fault location method has been widely applied in the power system because it's wide applicability and high accuracy [17].

Thus, this paper presents the technique to locate the fault area using traveling wave in Korean power transmission system. The proposed algorithm utilizes the application of PMUs and the propagation characteristics of traveling wave, and considers all areas in the Korean transmission system. 345 and $765 \mathrm{kV}$ of Korean power transmission systems are modeled by using Electro Magnetic Transient Program - Restructured Version (EMTP-RV). In the case of modeling of target network, the main facilities such as the generators, transformers, loads and transmission lines are modeled based on real data provided by KEPCO and Korea Power Exchange (KPX). In the modeled Korean power transmission system, the total system is divided into 63 clusters where can happen the fault event. Also, PMUs are deployed to measure voltage and current of transmission line and the number of PMUs is calculated by applying the concept of Depth Of Unobservability (DOU). Based on these conditions, fault area is estimated by the traveling wave-based method described in Section 2. To validate the suggested algorithm, the various simulations including the line faults, generator trip and load shedding situations are conducted and the simulation results are analyzed.

\section{Fault area estimation}

\subsection{Basic concept of fault area estimation}

To achieve the fault area estimation in wide area network, this paper models the ultra-high voltages national wide transmission network of Korea using EMTP-RV. In the modeled transmission network, PMUs are deployed to measure the voltages and the currents of the transmission line connected to the bus. The output signal of the PMU which is installed on the bus and the adjacent bus could be supervised through the voltages and currents measured from each of PMU. The number of PMU to be installed in the network is 19 which are calculated based on the concept of DOU. The faults events are not only transmission line faults but also generator trip and load shedding situations. The travelling wave is applied in the modeled system for detecting fault area. The aim of this study is applying the travelling wave theory as an approximate fault area estimation technique rather than positioning exact location.

\subsection{Selection of measurement points based on DOU}

In general, the required number of PMUs to monitor the whole wide area network system is about $1 / 5-1 / 4$ of a total number of buses in power system. In order to determine the optimal location for installing PMUs, the concept of observability is applied [21, 22]. The bus where the PMU is installed is called a directly observed bus. First neighbor buses of the directly observed bus are called observed buses, since their state can be obtained by PMU data and line parameters between directly observed buses. Other buses are called unobserved buses. DOU means the number of successive unobserved buses. This paper considers the concept of DOU for measuring of distance from observed buses to unobserved buses, as introduced in [21, 22].

The DOU concept is applied to select the optimal PMU measurement points in the power system. Figures 1 and 2 show the concepts of DOU 1 and DOU 2, respectively. In Fig. 1, the bus $\mathrm{B}$ and $\mathrm{F}$ are directly observed bus. Also, the bus $\mathrm{A}, \mathrm{C}, \mathrm{E}$, and $\mathrm{G}$ indicate observed bus, and bus $\mathrm{X}$ is unobserved bus. This system is called DOU 1 system because the number of successive unobserved buses is one. In Fig. 2, the bus $\mathrm{R}$ and $\mathrm{U}$ are directly observed bus. Also, the bus $\mathrm{Q}, \mathrm{S}, \mathrm{T}$, and $\mathrm{V}$ indicate observed bus, and bus $\mathrm{Y}$ 


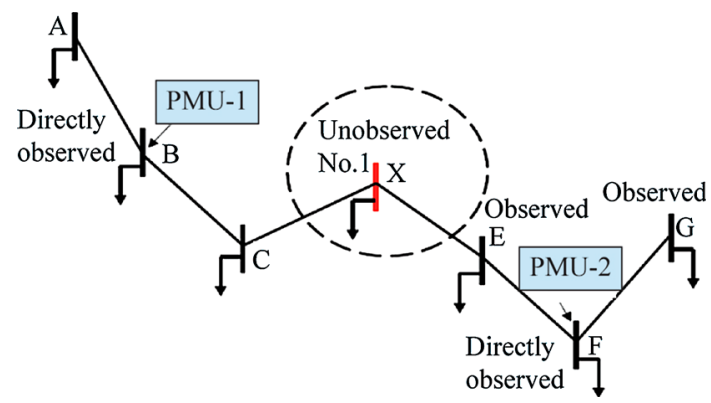

Fig. 1 Concept of DOU 1

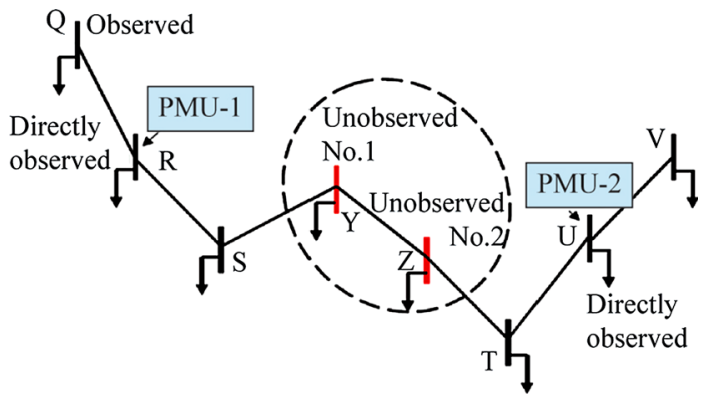

Fig. 2 Concept of DOU 2

and $\mathrm{Z}$ are unobserved bus. This system is called the DOU 2 system because the number of successive unobserved buses is two $[24,25]$.

According to the KEPCO's data, Korean power transmission system has 119 buses with $345 \mathrm{kV}$ and 5 buses with $765 \mathrm{kV}$ [23-25]. However, not all of them are taken into consideration in modeling. There are two cases where two buses were directly connected as a single bus. Two buses are considered as one single bus if the length of transmission line between them is less than a few kilometers for computational convenience. As a result, a total of 117 buses are included in the system modeling. The minimum number of PMUs required to monitor the whole system is calculated based on the DOU 1 system and DOU 2 system, as shown in Table 1. In this paper, DOU 1 is only considered because it gives better observability.

Table 1 Number of buses for two DOU cases

\begin{tabular}{lll}
\hline Cases & DOU 1 & DOU 2 \\
\hline Directly observed bus & 19 & 12 \\
Observed bus & 63 & 45 \\
DOU 1 bus & 35 & 44 \\
DOU 2 bus & - & 16 \\
Total Number. of bus & 117 & 117 \\
\hline
\end{tabular}

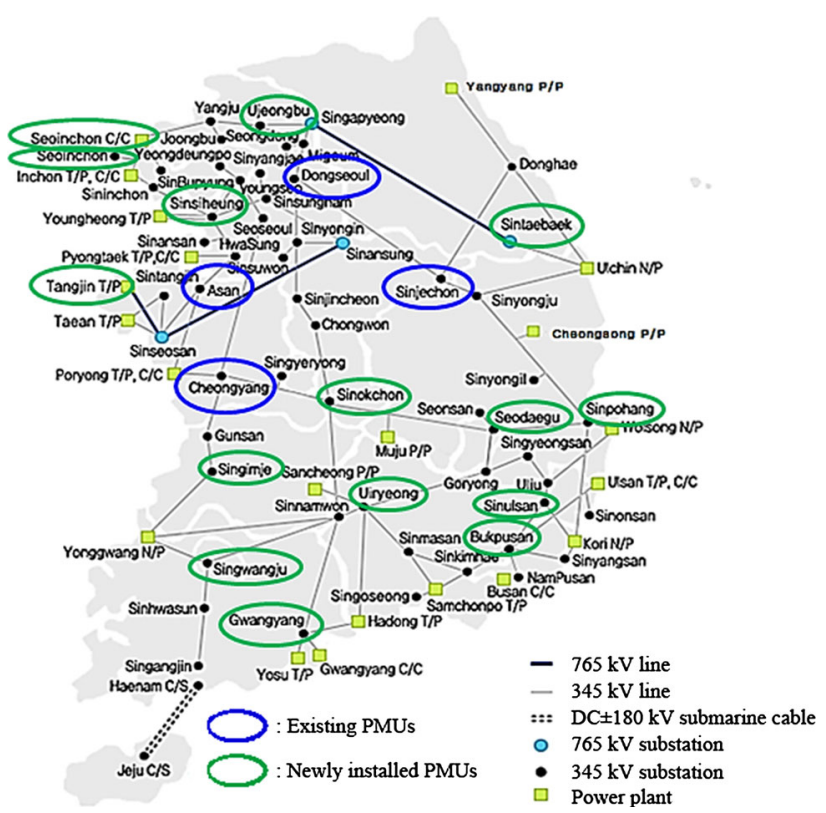

Fig. 3 Locations of PMUs in case of DOU 1

Figure 3 shows the locations of the PMUs in case of DOU 1. The blue and green ellipses indicate the existing PMUs and the newly installed PMUs, respectively.

\subsection{Traveling wave theory and fault area estimation}

The travelling wave theory has been applied to detect the fault occurrence and location for a long time. In this paper, the basic theory is applied for fault area estimation to reduce the sampling frequency level to $2.88 \mathrm{kHz}$, which is remarkable for identifying the fault area in the modeled system.

This method can detect the fault location and area by using the propagation velocity of traveling wave and the length of transmission line [26-28]. The estimation accuracy of fault area depends on the fault detection algorithm, the phase synchronization of the Global Positioning System (GPS) and the sampling frequency of Digital Fault Recorders (DFR) [22, 29].

Figure 4 illustrates a simple 2-bus transmission system to estimate the fault area using traveling wave. The parameter $l$ means the line length between Bus 1 and Bus 2 . If the fault occurs at a distance $d$ from Bus 1 at time $\mathrm{t}_{0}$, the DFRs immediately detect the line fault by obtaining fault signal.

The first detection time at Bus 1 and Bus 2 is $t_{11}$ and $t_{21}$, respectively. The fault distance $d$ can be derived as (3) based on (1) and (2).

$$
\begin{aligned}
& d=v\left(t_{11}-t_{0}\right) \\
& 1-d=v\left(t_{21}-t_{0}\right)
\end{aligned}
$$




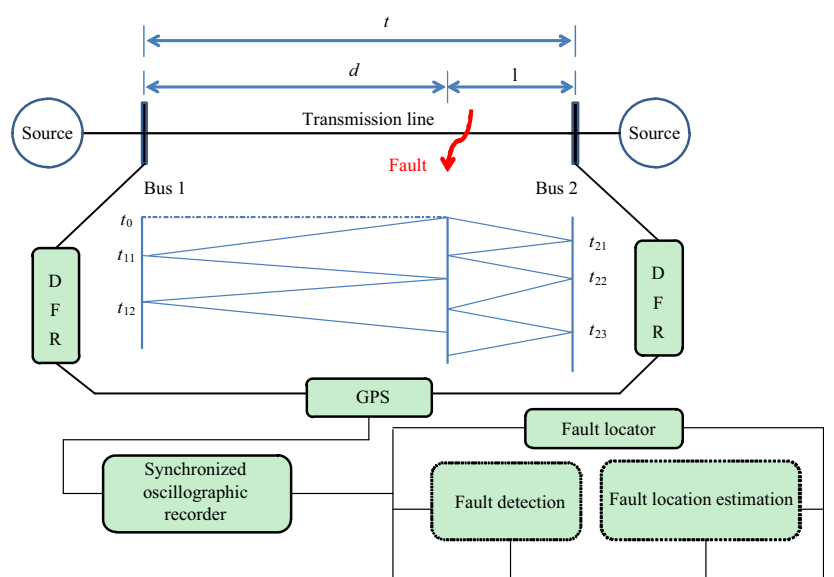

Fig. 4 Illustration of fault area estimation using traveling wave theory

$d=\frac{l+\left(t_{11}-t_{21}\right) v}{2}$

where $v$ means the propagation velocity of the traveling wave on the transmission line between Bus 1 and Bus 2 .

If the error $e$ called tolerance that occurs due to sampling frequency when applying traveling wave theory, it can be calculated as following equation.

$|e| \cong \frac{\Delta t \cdot c}{2}$

where $c$ means the propagation velocity of light. For example, the tolerance will be $52.08 \mathrm{~km}$ when the sampling frequency is $2.88 \mathrm{kHz}$.

\subsection{Fault area estimation in wide area network}

The purpose of suggested scheme is not for detecting exact fault location but for estimating approximate fault location by the low level of the sampling frequency of the travelling wave system. In order to improve the accuracy of the fault location, Korean national wide transmission network is divided into 63 clusters as shown in Fig. 5. The 19 PMUs are installed to get the voltage signal from the network and they are synchronized with the GPS. The sampling frequency is selected based on the error about $52 \mathrm{~km}$ that is considered as a real distance between each PMU. The traveling wave is applied to locate the fault area in the modeled system. The initiated signal from the travelling wave source will be transferred to the fault position and will be reflected. Each PMU will detect the reflected signal and output signal which are voltage value measured from the PMU. This value will be used by the algorithm as voltage signal. The 19 PMUs have to be synchronized with the GPS in the modeled system. The algorithm is formulated to determine which cluster the fault is located in among the 63 clusters.

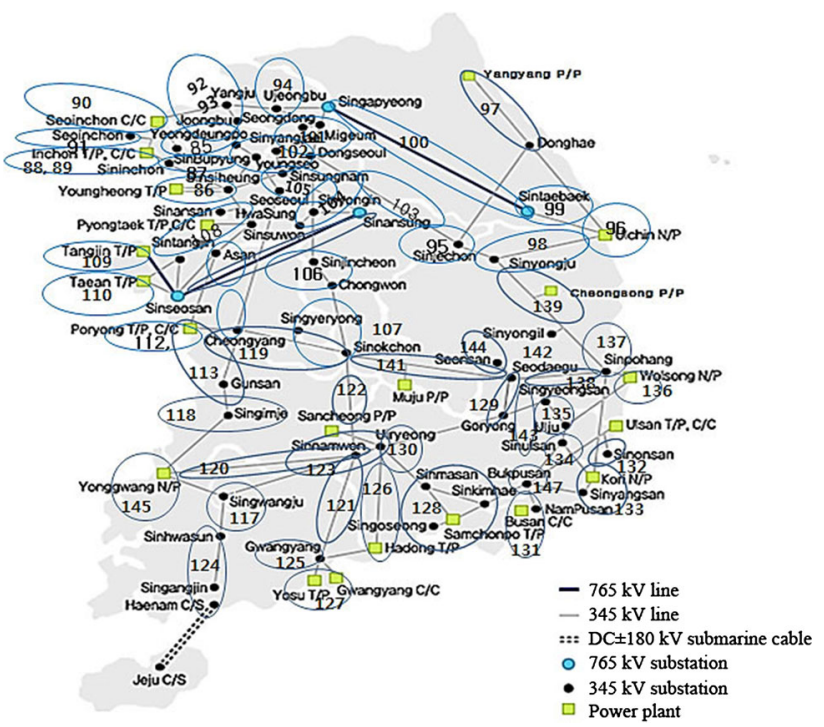

Fig. 5 Model system divided into 63 local areas

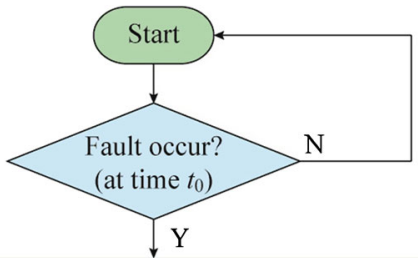

Recording the fault detection time $t_{1}$ at $1^{\text {st }}$ fault detection PMU's bus

Recording the fault detection time $t_{2}$ at the neighbor PMU's bus during one period from $t_{1}$

Calculating the fault distance by applying $t_{1}$ and $t_{2}$ into traveling wave theory

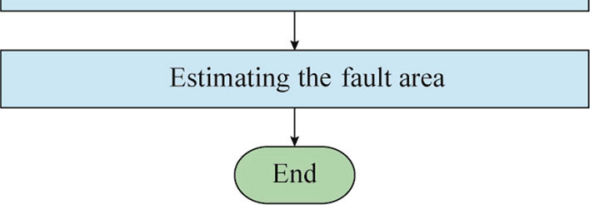

Fig. 6 Flow chart for estimating fault area

Figure 6 shows the algorithm for estimating the fault area. If the fault occurs at any area among the 19 areas, the PMU which is proximate to fault area will detect the fault firstly according to the traveling wave theory and classification method using Wavelet Singular Value Decomposition (WSVD). The voltage signal measured from PMU for the fault area estimation is processed. In the operation process of the algorithm, the threshold value is determined irrespective of voltage when there is white noise in signal and it is verified [30]. 
Since the fault is assumed to be in the vicinity of the first PMU, its neighbor PMUs need to calculate the fault distance from the first PMU. When the fault occurs between the first PMU and one of its neighbor PMUs, the fault distance is calculated according to (3).

If the calculated distance is below $50 \%$ of the real distance between the first PMU and the neighbor PMU, it is a valid fault distance. Otherwise, the fault is between the first PMU and another neighbor PMU. In this paper, the case study about fault area is only considered to Sinoxchun $3 \mathrm{~S}$. If Sinoxchun $3 \mathrm{~S}$ is the place where the fault is firstly detected at time $t_{18}$, the fault distance from PMUs located in the vicinity of Sinoxchun $3 \mathrm{~S}$ is calculated as shown in Table 2.

According to the traveling wave theory, the fault distance from Sinoxchun $3 \mathrm{~S}$ in Table 2 should be between 0 and half of its real distance from Sinoxchun $3 \mathrm{~S}$ if the fault occurs between Sinoxchun $3 \mathrm{~S}$ and the corresponding neighbor PMU. However, when the fault does not occur between Sinoxchun 3S and the corresponding neighbor PMU, the calculated fault distance would have a minus value.

Based on the calculated fault distance in Table 2, the fault area can be estimated as shown in Table 3. The first column in Table 3 indicates the order of procedure in locating the fault area. Only if the first estimation order is not satisfied to corresponding condition, the condition of next order is examined. And then the algorithm determines the fault area where the condition of the order is satisfied. The orders for each scenario are set up with certain stages of repetition to find the fault area. This is because the propagation of voltage fluctuation created by a fault is hard to predict due to its non-linearity and dependency on the power system operating conditions. Therefore, some of the areas are examined more than once in the estimation procedure as shown in Table 3. When the nearby PMUs do not detect the fault, the fault distance from Sinoxchun $3 \mathrm{~S}$ to

Table 2 Calculation of fault distance between Sinoxchun $3 \mathrm{~S}$ and its neighbor PMUs

\begin{tabular}{llll}
\hline $\begin{array}{l}\text { Neighbor } \\
\text { PMU }\end{array}$ & $\begin{array}{l}\text { Distance from } \\
\text { Sinoxchun } \\
\text { 3S }(\mathrm{km})\end{array}$ & $\begin{array}{l}\text { Fault } \\
\text { detection } \\
\text { time }\end{array}$ & $\begin{array}{l}\text { Fault distance from } \\
\text { the Sinoxchun 3S } \\
\text { to the neighbor } \\
\text { PMU }(\mathrm{km})\end{array}$ \\
\hline Seodaegu 3 & $l_{18_{1}}=116.36$ & $t_{18_{1}}$ & $L_{18_{1}}=\frac{l_{18_{1}}+c\left(t_{18}-t_{18_{1}}\right)}{2}$ \\
Singwangju 3 & $l_{18_{2}}=156.20$ & $t_{18_{2}}$ & $L_{18_{2}}=\frac{l_{18_{2}}+c\left(t_{18}-t_{18_{2}}\right)}{2}$ \\
Uiryeong 3 & $l_{18_{3}}=161.42$ & $t_{18_{3}}$ & $L_{18_{3}}=\frac{l_{18_{3}}+c\left(t_{18}-t_{18_{3}}\right)}{2}$ \\
Asan 3 & $l_{18_{4}}=177.85$ & $t_{18_{4}}$ & $L_{18_{4}}=\frac{l_{18_{4}}+c\left(t_{18}-t_{18_{4}}\right)}{2}$ \\
Chungyang 3 & $l_{18_{5}}=183.18$ & $t_{18_{5}}$ & $L_{18_{5}}=\frac{l_{18_{5}}+c\left(t_{18}-t_{18_{5}}\right)}{2}$ \\
Dongseoul 3 & $l_{18_{6}}=187.73$ & $t_{18_{6}}$ & $L_{18_{6}}=\frac{l_{18_{6}}+c\left(t_{18}-t_{18_{6}}\right)}{2}$ \\
Singimje 3 & $l_{18_{7}}=192.30$ & $t_{18_{7}}$ & $L_{18_{7}}=\frac{l_{18_{7}}+c\left(t_{18}-t_{18_{7}}\right)}{2}$ \\
Dangjin TP7 & $l_{18_{8}}=280.00$ & $t_{18_{8}}$ & $L_{18_{8}}=\frac{l_{18_{8}}+c\left(t_{18}-t_{18_{8}}\right)}{2}$ \\
\hline
\end{tabular}

Table 3 Procedure of fault area estimation when the fault is firstly detected at Sinoxchun $3 \mathrm{~S}$

\begin{tabular}{|c|c|c|c|}
\hline Order & $\begin{array}{l}\text { Area } \\
\text { no. }\end{array}$ & Area name & $\begin{array}{l}\text { Fault distance from } \\
\text { the Sinoxchun } 3 \mathrm{~S} \\
\text { to the neighbor PMU }(\mathrm{km})\end{array}$ \\
\hline 1 & 107 & Sinoxchun $3 \mathrm{~S}$ & $\begin{array}{l}\text { In case that } L_{18_{1}} \text { and } \\
L_{18_{8}} \text { are not calculated }\end{array}$ \\
\hline 2 & 112 & $\begin{array}{l}\text { Boryung T/P 3S } \\
\text { Boryung C/C } 3\end{array}$ & $\left(0<L_{18_{4}}\right)$ and $\left(0<L_{18_{5}}\right)$ \\
\hline 3 & 106 & $\begin{array}{l}\text { Sinjinchun } 3 \\
\text { Chungwon } 3 \\
\text { Ansung } 3\end{array}$ & $\begin{array}{r}\left(0<L_{18_{8}}<104\right) \\
\text { and }\left(0<L_{18_{6}}\right)\end{array}$ \\
\hline 4 & 146 & $\begin{array}{l}765 \mathrm{kV} \text { line between } \\
\text { Sinansung and } \\
\text { Singapyung }\end{array}$ & $\begin{array}{r}\left(104 \leq L_{18_{8}}\right) \text { or } \\
\left(0<L_{18_{6}}\right)\end{array}$ \\
\hline 5 & 141 & $\begin{array}{l}\text { Sinoxchun 3S- } \\
\text { Seodaegu } 3\end{array}$ & $0<L_{18_{1}}$ \\
\hline 6 & 122 & $\begin{array}{l}\text { Sinnamwon } 3 \text { area } \\
\text { (Gwangju-Namwon- } \\
\text { Oxchun) }\end{array}$ & $\begin{array}{r}\left(104 \leq L_{18_{8}}\right) \text { or } \\
\left(0<L_{18_{6}}\right)\end{array}$ \\
\hline 7 & 112 & $\begin{array}{l}\text { Boryung T/P } 3 \mathrm{~S} \\
\text { Boryung } \mathrm{C} / \mathrm{C} 3\end{array}$ & $0<L_{18_{4}}$ \\
\hline 8 & 116 & $\begin{array}{l}\text { Singyeryong } 3 \\
\text { Sinoxchun } 3\end{array}$ & $0<L_{18_{5}}$ \\
\hline 9 & 113 & $\begin{array}{l}\text { Boryung T/P } 3 \\
\text { Chungyang S } \\
\text { Gunsan } 3\end{array}$ & $0<L_{18_{7}}$ \\
\hline 10 & 107 & Sinoxchun $3 S$ & $\begin{array}{l}\text { All previous conditions } \\
\text { are not satisfied }\end{array}$ \\
\hline
\end{tabular}

each PMU in Table 3 is set to 0 as the fault distance is not calculated. The number $104 \mathrm{~km}$ of the order 3 and 4 in Table 3 means the distance from Sinoxchun $3 \mathrm{~S}$ that distinguishes the area No. 106 from the area No. 146.

\section{Simulation and discussions}

In this section, the modeling of Korean nationwide power transmission system in using EMTP-RV and the various simulations are discussed. The system parameters used in modeling are based on the real system data in PSS/ E files provided by KEPCO and KPX [23-25].

\subsection{Modeling of wide area transmission system in Korea}

\subsubsection{Target network}

The nominal voltages of the power transmission system in Korea are composed of 154,345 , and $765 \mathrm{kV}$. The target 
network considered in this paper includes 345 and $765 \mathrm{kV}$ transmission lines as shown in Fig. 7 [24, 25]. The transmission lines of $154 \mathrm{kV}$ are treated as loads.

The total load is 54,647 MVA (The active power is $54,300 \mathrm{MW}$ and the reactive power is $6150 \mathrm{Mvar}$ ). The total generation is $57,001 \mathrm{MVA}(55,070 \mathrm{MW}$ and 14,713 Mvar) and the loss of transmission lines over $154 \mathrm{kV}$ transmission system is about $2 \%$.

\subsubsection{Modeling of generator}

The target power transmission system has 159 generator units in total. Among them, 98 units are modeled with the full real data of KEPCO, while the other 61 units are missing some or all of their data, because some parts of the system were constructed many years ago. Therefore, four units of the Gwangyang Gas Turbines (G/T) and Unit 3 of the Gori Nuclear Power plant (N/P) are modeled using the data of other exciter and governor in their power plant complexes, respectively.

Eight units of the Seoinchun G/T are modeled with only generator and exciter data. Two units of the Cheongsong Power Plant (P/P), Units 1-4 of the Uljin N/P, Units 3 and 4 of the Yonggwang N/P, and two units of the Sancheong $\mathrm{P} / \mathrm{P}$ are modeled only with generator and governor data. Units 1 and 2 of the Inchun G/T, six units of the POSCO Combined Combustion $(\mathrm{C} / \mathrm{C})$, the Pyungtaig $\mathrm{C} / \mathrm{C}$ and nine units of the Thermal Power plants (T/P), four units of the the Yangyang P/P, Units 5 and 6 of the Uljin N/P, two units of the Yosu T/P, Units 1 and 2 of the Gori N/P, and nine

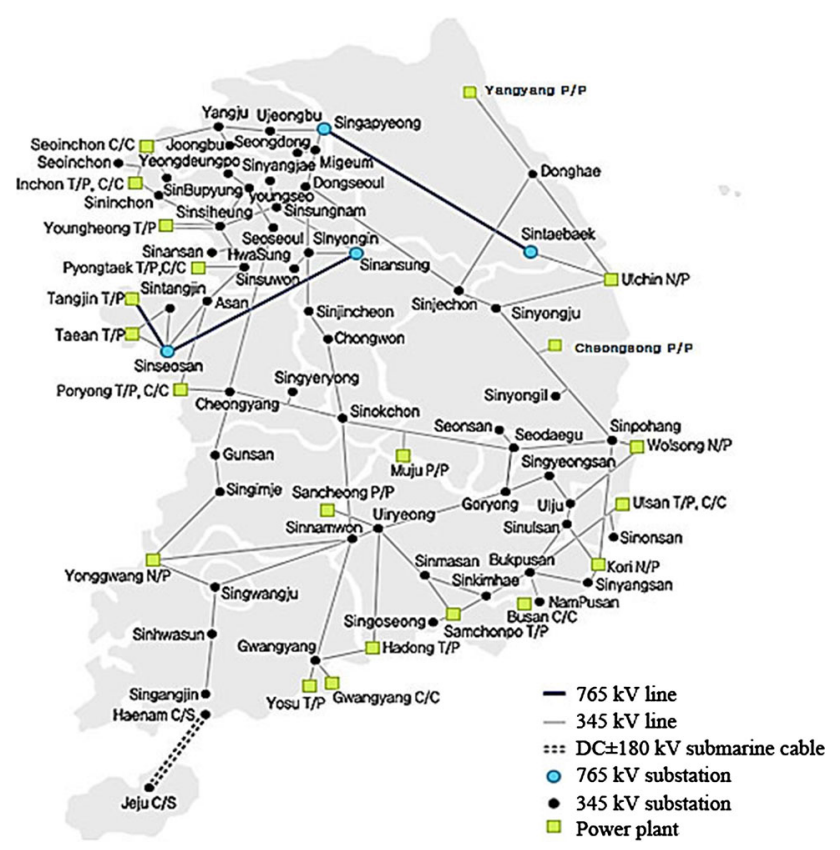

Fig. $7345 \mathrm{kV}$ and $765 \mathrm{kV}$ Korean power transmission system units of the Ulsan $\mathrm{C} / \mathrm{C}$ and $\mathrm{T} / \mathrm{P}$ are modeled only with generator data. Finally, Units 3 and 4 of the Inchun T/P are modeled with the data of Unit 2 of the Yongnam T/P, which has similar characteristics

\subsubsection{Modeling of transformer}

450 transformers which include the main transformers and generator's step-up transformers are modeled. Based on the built-in transformer model in EMTP-RV, the necessary data such as the nominal voltage, capacity, frequency, and equivalent impedance are inputted. The tap positions are set to comply with the operating condition of the summer peak season according to the load flow data of the PSS/E.

\subsubsection{Modeling of transmission line}

The simulation time step is set to $13.88 \mu$ s to see the impact of fault propagation. The current signal travels 4.17 $\mathrm{km}$ per one time step. Therefore, the constant parameter (CP) model is applied to transmission lines longer than 10 $\mathrm{km}$, even though $\mathrm{CP}$ models are generally applied to transmission lines longer than $100 \mathrm{~km}$. On the other hand, the lines shorter than $10 \mathrm{~km}$ are modeled with the $\pi$ model.

\subsubsection{Modeling of loads}

The static load model is used with steady-state load flow data such as the active power, reactive power, and voltages acquired by PSS/E simulations. Synchronized phasor angles of generators are also obtained from the load flow data of PSS/E, but they must be adjusted somewhat to make the system stable.

\subsubsection{Modeling and validation of wide area transmission system}

Figure 8 shows the wide area transmission system of Korea modeled by using EMTP-RV. The simulations are performed in steady state during $10 \mathrm{sec}$ in order to validate the performance of the modeled network. The power system frequency of modeled transmission system is measured at nine buses: Dongseoul No. 1, Sinsiheung No. 3, Asan No. 3, Sinjechun No. 3, Chungyang No. 3, Seodaegu No. 3, Uiryung No. 3, Singoangju No. 3 and Bukbusan No. 3s.

Figure 9 shows the measured frequency range in the modeled network. The lowest frequency is $59.9931 \mathrm{~Hz}$ at the Uiryung No. 3, and the highest frequency is $60.0002 \mathrm{~Hz}$ at the Seodaegu No. 3. As a range of measured frequencies varies within less than $0.01 \mathrm{~Hz}$, the modeled transmission network operates in a stable state. 


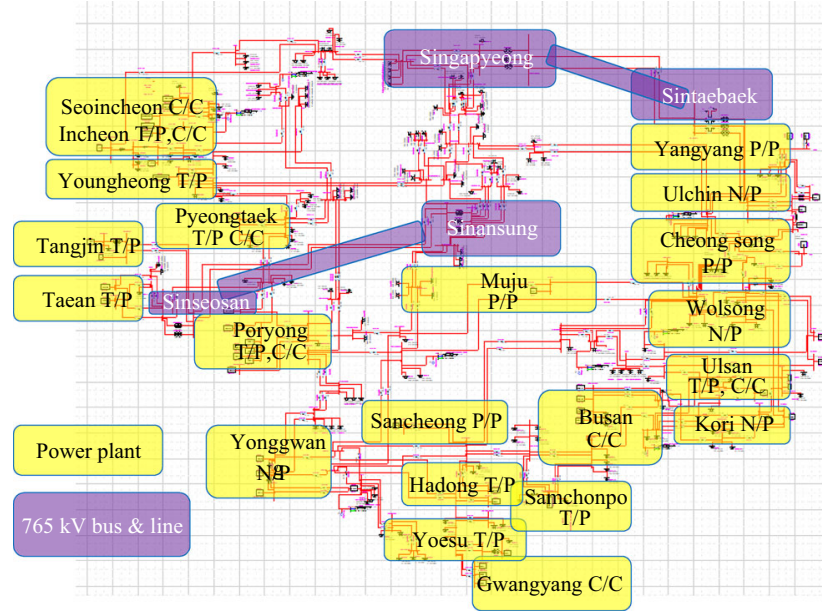

Fig. 8 Wide area power transmission system modeled by EMTP-RV

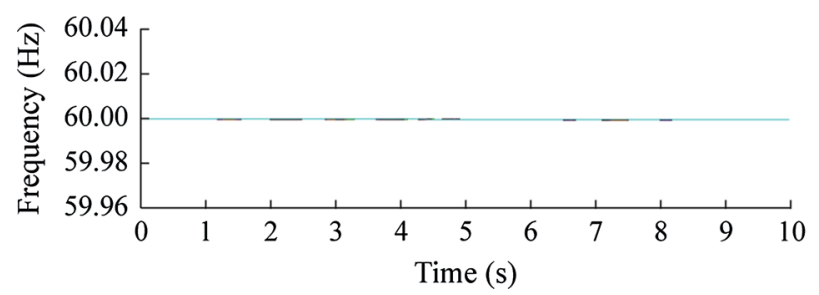

- Frequency_Asan 3; - Frequency_Bukbusan 3

- Frequency_CheongYang 3; - Frequency_DongSeoul 3

— Frequency_EuRyeong 3; — Frequency_SeoDaegu 3

- Frequency_SinSiheung 3; - Frequency_SinGwangju 3

— Frequency_SinJaecheon 3

Fig. 9 Measured frequencies in the modeled system

Table 4 compares the measured voltages and the original PSS/E data. The average difference between two sets of voltages is $0.71 \%$. From these results, it can be concluded that the wide area transmission system of Korea is well modeled.

\subsection{Simulation results}

As an example of fault area estimation, this paper presents the simulation results when the Double Line to Ground (DLG) fault with the fault resistance of $60 \Omega$ at $0.502 \mathrm{sec}$ occurs between the bus Chungwon 3 and the bus Sinjinchun 3. The exact fault area is $17.03 \mathrm{~km}$ from bus Chungwon 3 and $15 \mathrm{~km}$ from bus Sinjinchun 3 .

Figure 10 shows the verification result of the proposed algorithm when DLG fault occurs between bus Chungwon 3 and bus Sinjinchun 3. As shown in Fig. 10, the fault area is being estimated by algorithm during $0.00356 \mathrm{sec}$ from the fault time $0.502 \mathrm{sec}$ and then the accurate fault area No. 106 is identified at $0.50556 \mathrm{sec}$. This shows that the algorithm can rapidly identify the exact fault area after the fault inception.
Table 4 Voltage difference between the modeled network and original data

\begin{tabular}{|c|c|c|c|}
\hline Area name & $\begin{array}{l}\text { Measured voltage } \\
\text { (p.u.) }\end{array}$ & $\begin{array}{l}\text { PSS/E } \\
\text { voltage } \\
\text { (p.u.) }\end{array}$ & $\begin{array}{l}\text { Difference } \\
(\%)\end{array}$ \\
\hline Boryung TP3 & 1.0282 & 1.0308 & -0.25 \\
\hline Boryung TP3S & 1.0273 & 1.0301 & -0.27 \\
\hline Boryung CC3 & 1.0282 & 1.0308 & -0.25 \\
\hline Boryung TP78 & 1.0213 & 1.0234 & -0.21 \\
\hline Cheongsong PP & 1.0325 & 1.0331 & -0.05 \\
\hline Dangjin TP3 & 1.0084 & 1.0045 & 0.39 \\
\hline Dangjin TP7 & 1.0012 & 1.0017 & -0.05 \\
\hline Gori \#1 & 1.0237 & 1.0246 & -0.09 \\
\hline Gori \#2 & 1.0298 & 1.0276 & 0.21 \\
\hline Goangyang CC & 1.0458 & 1.0323 & 1.3 \\
\hline Hadong TP3 & 1.0388 & 1.0322 & 0.64 \\
\hline Hadong TP3S & 1.0389 & 1.0287 & 0.99 \\
\hline Inchun TP3S & 1.0417 & 1.0314 & 1 \\
\hline InchunTP3 & 1.0393 & 1.0335 & 0.56 \\
\hline Mooju PP & 1.0278 & 1.032 & -0.41 \\
\hline Seobusan 3 & 1.0414 & 1.0321 & 0.9 \\
\hline Pyungtaig TP3 & 1.0155 & 1.0159 & -0.04 \\
\hline Sanchung PP & 1.0288 & 1.0241 & 0.46 \\
\hline Samchunpo TP & 1.0216 & 1.0207 & 0.08 \\
\hline Seoinchun CC & 1.0414 & 1.0309 & 1.02 \\
\hline Sininchun CC & 1.0448 & 1.034 & 1.04 \\
\hline Taian TP3 & 1.0241 & 1.0343 & -0.98 \\
\hline Taian TP3S & 1.0231 & 1.034 & -1.05 \\
\hline Uljin \#1 & 1.0105 & 1.0316 & -2.04 \\
\hline Uljin \#2 & 1.0102 & 1.0314 & -2.06 \\
\hline Uljin \#3 & 1.0099 & 1.0332 & -2.25 \\
\hline Ulsan TP & 1.0342 & 1.0348 & -0.06 \\
\hline Wolsung NP3 & 1.0215 & 1.0227 & -0.12 \\
\hline Wolsung NP3S & 1.0169 & 1.0234 & -0.63 \\
\hline Yosu TP1 & 1.0179 & 1.0364 & -1.79 \\
\hline Yangyang PP & 1.0475 & 1.0306 & 1.64 \\
\hline $\begin{array}{l}\text { Yeonggwang } \\
\text { NP\#1 }\end{array}$ & 1.0235 & 1.0295 & -0.59 \\
\hline $\begin{array}{l}\text { Yonggwang } \\
\text { NP\#2 }\end{array}$ & 1.0236 & 1.0297 & -0.6 \\
\hline $\begin{array}{l}\text { Yonggwang } \\
\text { NP\#3 }\end{array}$ & 1.0237 & 1.0311 & -0.72 \\
\hline $\begin{array}{l}\text { Yeongheong } \\
\text { TP3 }\end{array}$ & 1.024 & 1.0251 & -0.11 \\
\hline Average & \multirow{2}{*}{\multicolumn{3}{|c|}{0.71}} \\
\hline Difference $(\%)$ & & & \\
\hline
\end{tabular}

100 cases of faults are tested to verify the performance of the proposed algorithm: 1) 63 cases of line faults, including single-line-to-ground, double-line-to-ground, three-phase short, and double-line short; 2) 22 cases of generator trip, with the range of generation between 510-2400 MVA; 3) 15 cases of load shedding, with the 


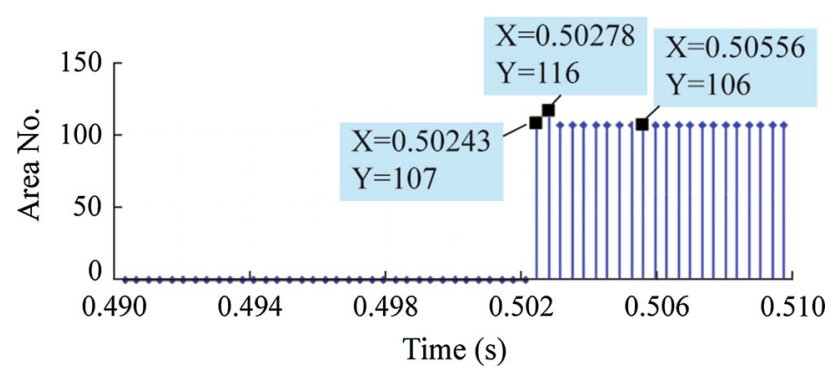

Fig. 10 Fault area when DLG fault occurs between Chungwon 3 bus and Sinjinchun 3 bus

Table 5 Simulation conditions and results

\begin{tabular}{lllll}
\hline Fault type & $\begin{array}{l}\text { Number of } \\
\text { cases }\end{array}$ & \multicolumn{2}{l}{ Number of fault area estimation cases } \\
\cline { 3 - 5 } & & Success & $\begin{array}{l}\text { Marginal } \\
\text { success }\end{array}$ & Fail \\
\hline Line fault & 63 & 52 & 7 & 4 \\
Generator trip & 22 & 17 & 2 & 3 \\
Load shedding & 15 & 8 & 5 & 2 \\
Total & 100 & 77 & 14 & 9 \\
\hline
\end{tabular}

Note Success rate (including success and marginal success) $=91 \%$

range of load between 210-360 MVA. The simulation conditions and results are presented in Table 5 . The possibility of failure in the fault area estimation is just $9 \%$. From these results, it can be seen that the proposed algorithm does not work well with small amounts of load shedding because they are too small to be observed in the power system. However, a larger amount of load shedding can be detected enough by the proposed algorithm.

The reasons of failures are considered as that the level of the sampling frequency of the travelling wave system, the influence of reflection /refraction of the traveling wave and the characteristics of the power transmission network. Optimizing the sampling frequency level and number of PMU are considered as the ways to improve the success rate of fault area estimation.

\section{Conclusions}

In this paper, the modeling of the 345 and $765 \mathrm{kV}$ Korean nationwide power transmission system using EMTP-RV has been described based on real data in PSS/E files provided by KEPCO and KPX. To estimate the accurate fault area, the technique based on traveling wave is suggested. The proposed algorithm not only applies traveling wave theory and but also considers the application of PMUs and the concept of DOU. Based on the above contents, the verification of fault area estimation technique is conducted under various simulation conditions. As a result, the accuracy of fault area estimation tends to be very high $(91 \%)$ for the all cases considered in this study. If the greater number of PMUs is installed in modeled system, the accuracy of fault area estimation will increase greatly. In addition, the reduction of the tolerance range in application of travelling wave theory will help to improve the performance of proposed algorithm.

Acknowledgment This work was supported by the National Research Foundation of Korea (NRF) grant funded by the Korea government (MSIP) (No. 2015R1A2A1A10052459).

Open Access This article is distributed under the terms of the Creative Commons Attribution 4.0 International License (http:// creativecommons.org/licenses/by/4.0/), which permits unrestricted use, distribution, and reproduction in any medium, provided you give appropriate credit to the original author(s) and the source, provide a link to the Creative Commons license, and indicate if changes were made.

\section{References}

[1] Martin KE, Benmouyal G, Adamiak MG et al (1998) IEEE standard for synchrophasors for power systems. IEEE Trans Power Deliv 13(1):73-77

[2] Phadke AG, Thorp JS (2008) Synchronized phasor measurements and their applications. Springer, Boston

[3] Martin KE, Carrol JR (2008) Phasing in the technology. IEEE Power Energy Mag 6(5):24-33

[4] Novosel D, Madani V, Bhargava B et al (2008) Dawn of the grid synchronization. IEEE Power Energy Mag 6(1):49-60

[5] Qiu B, Chen L, Centeno V et al (2001) Internet based frequency monitoring network (FNET). In: Proceedings of the 2001 IEEE Power Engineering Society winter meeting, vol 3, p 1166-1171. Columbus, 28 Jan-1 Feb 2001

[6] Zhong ZA, Xu CC, Billian BJ et al (2005) Power system frequency monitoring network (FNET) implementation. IEEE Trans Power Syst 20(4):1914-1921

[7] Kook KS, Liu Y, Bang MJ (2008) Global behavior of power system frequency in Korean power system for the application of frequency monitoring network. IET Gener Transm Distrib 2(5):764-774

[8] Abur A, Exposito AG (2004) Power system state estimation: theory and implementation. Marcel Dekker Inc, New York

[9] Liu GP, Venkatasubramanian V (2008) Oscillation monitoring from ambient PMU measurements by frequency domain Decomposition. In: Proceedings of the 2008 IEEE international symposium on circuits and systems, Seattle, 18-21 May 2008, pp 2821-2824

[10] Hashiguchi T, Yoshimoto M, Mitani Y et al (2003) Oscillation mode analysis in power systems based on data acquired by distributed phasor measurement units. In: Proceedings of the 2003 international symposium on circuits and systems (ISCAS'03), vol 3, Bangkok, 25-28 May 2003, pp 367-370

[11] Liu Z, Chen Z, Sun HS et al (2015) Multi-agent system-based wide-area protection and control scheme against cascading events. IEEE Trans Power Deliver 30(4):1651-1662

[12] Kalantar Neyestanaki M, Ranjbar AM (2015) An adaptive PMU-based wide area backup protection scheme for power transmission lines. IEEE Trans Smart Grid 6(3):1550-1559 
[13] Jena MK, Samantaray SR, Panigrahi BK (2015) A new widearea backup protection scheme for series-compensated transmission system. IEEE Syst J. doi:10.1109/JSYST.2015.2467218

[14] Eldin ESMT (2010) Fault location for a series compensated transmission line based on wavelet transform and an adaptive neuro-fuzzy inference system. In: Proceedings of the 2010 electric power quality and supply reliability conference (PQ'10), Kuressaare, 16-18 Jun 2010, p 229-236

[15] Othman MF, Mahfouf M, Linkens DA (2004) Transmission lines fault detection, classification and location using an intelligent power system stabiliser. In: Proceedings of the 2004 IEEE international conference on electric utility deregulation, restructuring and power technologies (DRPT'04), vol 1, Hong Kong, 5-8 Apr 2004, pp 360-365

[16] Gopalakrishnan A, Kezunovic M, McKenna SM et al (2000) Fault location using the distributed parameter transmission line model. IEEE Trans Power Deliver 15(4):1169-1174

[17] Chen Y, Liu D, Xu BY et al (2010) Wide area travelling wave fault location in the transmission network. In: Proceedings of the 2010 China international conference on electricity distribution (CICED'10). Nanjing, 13-16 Sept 2010, 6 pp

[18] Tawfik MM, Morcos MM (1999) A fault locator for transmission lines based on Prony method. In: Proceedings of the 1999 IEEE Power Engineering Society summer meeting, vol 2, Edmonton, 18-22 Jul 1999, pp 943-947

[19] Dalcastagne AL, Zimath SL (2008) A study about the sources of error of impedance-based fault location methods. In: Proceedings of the 2008 IEEE/PES transmission \& distribution conference and exposition: Latin America, 13-15 Aug 2008, 6 pp

[20] Wang B, Dong XZ, Bo ZQ (2008) A novel impedance fault location algorithm for UHV transmission lines. In: Proceedings of the IET 9th international conference on developments in power system protection (DPSP'08), Glasgow, 17-20 Mar 2008, pp 291-295

[21] Baldwin TL, Mili L, Biosen MB et al (1993) power system observability with minimal phasor measurement placement. IEEE Trans Power Syst 8(2):701-715

[22] Nuqui R (2009) Electric power grid monitoring with synchronized phasor measurements: Deployment and applications of wide area measurement systems. VDM-Verlag, Berlin

[23] Index parameter of the power transmission system in 2009. System Operation Department, Korea Power Exchange (KPX), Seoul, Republic of Korea, 2009

[24] Kim YS, Kim CH, Ban WH et al (2013) A comparative study on frequency estimation methods. J Electr Eng Technol 8(1):70-79

[25] Park CW, Shin DK, Kim CH et al (2011) Study on advanced frequency estimation technique using gain compensation. J Electr Eng Technol 6(4):439-446

[26] Zeng XJ, Chen N, Li ZW et al (2008) Network-based algorithm for fault location with travelling wave. P CSEE 28(31):48-53

[27] Xu BY, Li J, Chen P et al (2001) Modern travelling wave based fault location technology and its application. Autom Electr Power Syst 25(23):62-65

[28] Lopes FV, Fernandes D Jr, Neves WLA (2011) Fault location on transmission lines based on travelling waves. In: Proceedings of the 2011 international conference on power system transients (IPST'11), Delft 14-17 Jun 2011, 6 pp

[29] Nuqui RF (2001) State estimation and voltage security monitoring using synchronized phasor measurements. Ph D Thesis, Virginia Polytechnic Institute and State University, Burrus Hall, Blacksburg
[30] Lee JW, Kim WK, Oh YS et al (2015) Algorithm for fault detection and classification using wavelet singular value decomposition for wide-area protection. J Electr Eng Technol 10(3):729-739

Jae-Won LEE was born in Republic of Korea, 1954. He received his B.S. in electrical and computer engineering from Sungkyunkwan University, Suwon, Republic of Korea in 1975 and M.S. degree in engineering from Yonsei University, Seoul, Republic of Korea in 1989. He is now working toward his Ph.D. degree at Sungkyunkwan University in Republic of Korea. He was in charge of facility design, operation and management at Plant Engineering for 25 years. Currently, he is working as a Principal Engineer at Seoul EM Co., Ltd in Republic of Korea. His research interests include power system protection, analysis and system design. Mr. Lee is a Registered Professional Engineer in Republic of Korea and APEC Engineering Associations.

Won-Ki KIM was born in Republic of Korea, 1987. His research interests include power system transients, protection and stability. $\mathrm{He}$ received his B.S and M.S degrees in School of Electrical and Computer Engineering from Sungkyunkwan University, Republic of Korea, 2010 and 2012. Currently, he is working at Daewoo Shipbuilding \& Marine Engineering Co., Ltd in Republic of Korea.

Joon HAN was born in Korea, 1986. He received his B.S degree in School of Electrical Engineering from Soonchunhyang University, Republic of Korea, 2011 and M.S degree in College of Information and Communication Engineering from Sungkyunkwan University, Republic of Korea, 2013. At present, he is working on his Ph. D thesis at Sungkyunkwan University. His research interests include power system transients, protection, ESS and DC distribution system.

Won-Hyeok JANG received his B.S. and M.S. in Electrical and Computer Engineering from Sungkyunkwan University, Suwon, Republic of Korea in 2008 and 2010, respectively. He is now working toward his Ph.D. degree at University of Illinois at UrbanaChampaign. He is a Research Assistant in Electrical and Computer Engineering Department, University of Illinois at Urbana-Champaign. His research interests include power system modeling and analysis.

Chul-Hwan KIM (M'90-SM'04) was born in Republic of Korea in 1961. He received the B.S., M.S., and Ph.D. degree in electrical engineering from Sungkyunkwan University, Suwon, Republic of Korea in 1982, 1984, and 1990, respectively. In 1990, he joined Cheju National University, Cheju, Republic of Korea, as a Full-Time Lecturer. He was a Visiting Academic at the University of Bath, Bath, U.K., in 1996, 1998, and 1999, respectively. He has been a Professor in the College of Information and Communication Engineering, Sungkyunkwan University, since 1992. Currently, he is a Director with the Center for Power IT (CPIT) at Sungkyunkwan University. His research interests include power system protection, artificialintelligence applications for protection and control, modeling/protection of transmission \& distribution system, and electromagnetic transient phenomenon. 